\title{
PARA UMA NOVA FIGURAÇÃO DA PRÁXIS: \\ A TEORIA SOCIAL E O PRINCÍPIO DO COMUM'
}

\section{TOWARDS A NEW SHAPE OF PRAXIS: SOCIAL THEORY AND THE PRINCIPLE OF THE COMMON}

Felipe Ziotti Narita*

DARDOT, Pierre; LAVAL, Christian. Commun: essai sur la révolution au XXIe siècle. Paris: La Découverte, 2015. 593 p.

Publicado em 2014, contando com versão em e-book em 2015a, ${ }^{2}$ o livro Commun: essai sur la révolution au XXIe siècle (Comum: ensaio sobre a revolução no século XXI) de Pierre Dardot e Christian Laval analisa certa apreensão de um sentido histórico decorrente das transformações no sistema-mundo capitalista neste início de século XXI, bem como suas implicações sobre o agir político e a dinâmica social. Não se trata propriamente de um "diagnóstico de época”, mas sobretudo de uma reflexão sobre certas condições da ação política à luz de uma formulação conceitual capaz de reformular uma teoria crítica do capitalismo contemporâneo. Dardot e Laval constroem um esquema analítico contraposto a torções ideológicas implícitas nas narrativas dos anos 1980 e 1990 sobre a transição e o triunfo das democracias liberais capitalistas (SOWA, 2012; LUKIC, MASLOV,

*Pesquisador (CPI) de pós-doutorado da Universidade de São Paulo (USP), com doutorado em História pela Universidade Estadual Paulista "Júlio de Mesquita Filho" (UNESP). Professor do Programa de Pós-Graduação em Planejamento e Análise de Políticas Públicas - UNESP (São Paulo/SP/BR). fznarita@usp.br/fznarita@gmail.com.

1. 0 autor agradece a Krystian Szadkowski (Universidade Adam Mickiewicz, Polônia) e a Sérgio Fonseca (USP) pela constante interlocução teórica sobre o tema.

2. A página das citações segue a paginação do e-book no aparelho de leitura Kobo. Como a paginação depende das configurações de cada aparelho, nas referências de citação também indicarei, ao lado da página, o capítulo onde se encontra o trecho referenciado (o livro no e-reader Kobo conta a numeração das páginas dentro de cada capítulo, recomeçando a contagem a cada mudança de capítulo). 
2014), na medida em que, longe de neutralizar a contingência das experiências sociais sob o guarda-chuva de uma transição, ou de evidenciar a efetivação de uma ideia como sentido inscrito em uma racionalidade do processo da história, os anos 1990 assinalariam justamente uma ambivalência na razão neoliberal, por meio da rearticulação de projetos de emancipação fundamentados em disputas pelo espaço público, em críticas à flexibilização dos mercados e em questionamentos políticos sobre a apropriação de recursos naturais e distribuição de bens/ riquezas (vide as críticas à globalização, as manifestações contra os ajustes estruturais do FMI na América Latina, as propostas alter-mundialistas e ecologistas etc.).

A hipótese central dos autores é que, em uma conjuntura de "predação generalizada orquestrada pelas oligarquias que concentram a riqueza coletiva" (DARDOT; LAVAL, 2015a, p. 4 - Cap. 1), o princípio do comum é pensado justamente como uma nova razão política. 0 comum é uma instituição, ou seja, "um objeto da atividade política" compartilhado por demandas e princípios de autogoverno de coletividades - uma co -atividade elaborada sobre uma lógica social que "designa uma tarefa histórica de reinstituição democrática da sociedade” -, (DARDOT; LAVAL, 2015c, p. 314). Não se trata de uma gestão, uma vez que o autogoverno do comum não se limita ao governo de bens comuns, mas de um autogoverno no sentido da autonomização da organização social dos indivíduos, instituições e regras (DARDOT; LAVAL, 2015a, p. 4 - Proposição Política 1): uma nova potencialidade do agir, fundamentando uma atividade comum (agir commun) e a autonomia de sua forma social em relação ao domínio do mercado e da lógica concorrencial (portanto, por meio de uma crítica à agenda neoliberal das últi- mas duas décadas, Dardot e Laval entendem o princípio do comum como o fundamento de uma organização democrática co-determinada pelos participantes). Trata-se, a rigor, de uma alternativa política de organização social que, rechaçando o mercado como modelo universal e a propriedade burocrática do Estado, pretende indicar um novo sentido para um projeto de emancipação no século XXI.

Se o comum é a atividade que funda novas potencialidades da ação política (afinal, ele é entendido como princípio e instituição), a grande questão da démarche de Dardot e Laval é como a instituição pode ser convertida em práxis, ou seja, atividade social estruturada no sentido da emancipação. A resposta implica a análise de um longo percurso conceitual. De partida, apesar da arguta crítica feita por Toni Negri (2014) aos autores franceses sobre as implicações da desmaterialização do comum entendido com princípio (como engendramento da ação política), esvaziando assim o próprio entendimento da luta de classes (no sentido de Marx) e as novas dinâmicas históricas da exploração, convém dissociar a fundamentação lógica do real na subsunção marxiana (núcleos da ótima crítica de Negri) de sua abstração do processo histórico. A separação dessas duas dimensões é fundamental para a análise do trajeto teórico dos autores. 0 princípio do comum, nesse sentido, não é apenas um momento (ou uma figura) da reprodução ampliada do capital, mas uma potencialidade de instituição que indica uma apreensão teórica do sentido da ação política à luz do processo da história e da dinâmica social no capitalismo neoliberal.

Para Dardot e Laval (2015a, p. 5 - Cap. 2), a modernidade reelaborou e desenvolveu três grandes modelos (no sentido de ti- 
pos-ideais, ou seja, sínteses intelectuais) de apreensão do comum: comunidade de bens (utopia que remonta à Antiguidade, com a unidade buscada na igualdade e na recusa a toda forma de propriedade), associação de produtores (diferenciação social das atividades coordenada pela justiça e mérito assegurados pela democracia da gestão) e Estado burocrático (determinação da sociedade pela burocracia estatal). A tipologia, a bem da verdade, é bastante debitária da dissociação durkheimiana entre comunismo e socialismo (baseada em diferentes formas de realização da coesão social e da organização coletiva das funções socioeconômicas), de modo que, para os propósitos de Dardot e Laval, ela serve para dissociar o princípio do comum das três matrizes indicadas, na medida em que o comum não é um ideal originário a ser retomado nem um objeto apreendido exteriormente pela socialização do processo de produção - tampouco uma realização a partir da propriedade do Estado. Em relação a este último ponto, aliás, o argumento dos autores, desenvolvendo o modelo de análise de Marc Ferro, assinala junto aos caminhos revolucionários do século XX (leninismo, stalinismo, polpotismo e maoísmo) uma dupla burocratização que sequestrou a experiência do comum pelo alto (colonização dos órgãos populares) e por baixo (aparelho burocrático que sufoca as atividades sociais). A determinação da organização social pela agência do Estado, portanto, representa o esgotamento do ciclo revolucionário aberto em 1917.

Sobre as ruínas do comunismo estatizante nos anos 1980, em um ciclo histórico de desmanche do Estado de bem-estar e de desarticulação do social como campo de déficits corrigidos pelo Estado, as lutas sociais pelo comum fundamentam uma nova orientação histórica para a ação política e a organização social (DARDOT; LAVAL, 2015a, p. 14 - Cap. 3). 0 princípio do comum - a priori pensado na práxis social como uma comunidade de uso coletivo de bens e recursos (ou seja, como comuns) contra as privatizações e mercantilizações do capitalismo neoliberal -, ilustra a primeira figura do fundamento de uma retomada coletiva e democrática dos recursos e espaços subsumidos pela reprodução ampliada do capital. Das águas ao problema das cooperativas, das disputas pelo espaço urbano à crise de representação política (envolvendo narrativas antagônicas sobre "o povo" à luz da crise capitalista e do momento populista nas democracias liberais), as multidões de Madri, Barcelona, Nova York, Cairo, Istambul, São Paulo e Atenas apresentam agendas que, malgrado a difusão de pautas, tangenciam o controle de recursos e sua apropriação em diversas dimensões (serviços públicos, democracia participativa, gestão democrática de recursos e instituições etc.). Dardot e Laval (2015a, p. 7 - Cap. 4), por meio de uma crítica decisiva à célebre teoria dos comuns de Elinor Ostrom (que esvaziaria o problema de qualquer potencial de reorganização social tratando-o nos limites de um liberalismo confiante na racionalidade da agência individual, ou seja, como pluralidade de atividades e direitos de propriedade), pensam o comum como racionalidade alternativa generalizável pelas próprias pré-disposições da reprodução ampliada do capital.

Para Dardot e Laval, a difusão das lutas e dos movimentos sociais assinala um Zeitgeist que, a um só tempo, pode ser apreendido como um impasse político e uma alternativa de emancipação. Se o impasse reside no esgotamento das alternativas políticas do século XX e no desgaste do capitalismo neoliberal, a potência de emancipação 
implica uma teoria sobre o comum como eixo que orienta a estruturação da forma social no capitalismo contemporâneo, de modo que, para além dos comuns (pensados no plural como gestão e uso coletivo de recursos), o princípio do comum articula estruturalmente um salto qualitativo junto às reivindicações políticas globais. A interdependência entre as reivindicações setoriais e suas pautas difusas e a constituição do capitalismo neoliberal como uma dinâmica internacional implicam uma discussão sobre a dimensão da reprodução do capital. Trata-se de um processo contínuo de separação dos indivíduos das condições e meios herdados, dissociando modos de vida de qualquer tipo de autonomia em relação ao aparelho capitalista de produção e de consumo (DARDOT; LAVAL, 2015a, p. 32 - Cap. 3). A ação que institui o comum, portanto, lida com o impasse da instituição autônoma da forma social e de sua heteronomia historicamente constituída sob a reprodução ampliada do capital. Este problema pode ser abordado em duas dimensões: 1 - um conceito operacional de neoliberalismo que permita uma teoria crítica de seus desdobramentos sobre a dinâmica social, e 2 - a instituição do comum como princípio de ação, ou seja, como atividade desmaterializada que constrói o horizonte de potencialidades políticas e de autonomia do comum dentro de uma situação histórica determinada.

Para os autores, um conceito operacional de neoliberalismo deve abandonar a pura negatividade da despossessão (déposséssion) e do desmantelamento (démantèlement) do campo do social, bem como ficar afastado de um entendimento puramente dirigido ao capital financeiro e seus ativos. Esses dois lados são analisados como momentos de um processo social muito mais amplo. Pensado como uma estrutura de dispositivos, trata-se antes de uma governamentalidade (gouvernementalité) neoliberal - uma economia entendida como um corte transversal na sociedade, ou seja, um governo dos homens e das coisas, uma racionalidade que configura certos modos de ser da reprodução social estruturalmente vinculada à reprodução ampliada do capital (DARDOT; LAVAL, 2015a, p. 19 - Cap. 3). Se os dispositivos são difusos e transversais no conjunto social, as dinâmicas de luta não estão concentradas apenas nos núcleos de produção, mas são práticas dispersas na estrutura global desenvolvida pelo cosmo-capital (uma lógica de autoengendramento do valor a partir dos dispositivos de governamentalidade) em sua reprodução. A rigor, existe uma produção contínua da própria dinâmica social em um processo de subordinação a um cosmo-capital, cujo engendramento se autonomiza em escala global. 0 problema do comum - explícito a partir dos anos 1990 -, nesse sentido, é estruturalmente vinculado a essas práticas sociais difusas e globalizadas pela própria reprodução do capital, constituindo as formas disseminadas de resistência à subsunção da sociedade sob o capital.

Por meio de uma arqueologia teórica sobre o comum, Dardot e Laval traçam leituras bastante sui generis de Proudhon e de Marx. Em Proudhon, a ideia da força coletiva (uma força imanente que fundamenta a sociedade) cuja exploração é um roubo alicerçado no princípio da propriedade, de modo que o associacionismo proudhoniano antecipa a relação entre o comum e sua instituição. Marx indica que o comum é produto do capital e de seu desenvolvimento sobre o processo de trabalho, de modo que a força coletiva não está mais imanente à dinâmica social, mas deve ser produzida 
(façonnée) na reprodução do capital, que é engendrado pelo trabalho coletivo - a "atividade comum" (gemeinsame Tätigkeit) do Manifesto de 1848. A teoria da exploração de Marx, então, implica que o roubo não seja visto como a apropriação de uma força coletiva autonomizada na sociedade, já que essa atividade comum é reproduzida em função do capital, constituindo assim o núcleo da dialética materialista que integra os processos de trabalho e o proletariado à extração do mais-valor e ao circuito do capital (ativando a própria "subjetividade antagônica” como momento de desenvolvimento). A estreita dependência da reprodução ampliada do capital ao processo de produção material da vida representa um impasse para a teoria da instituição de Dardot e Laval: ambos afirmam que a produção é apenas uma dentre as diversas atividades do conjunto social (ideia que implica um deslocamento do problema do comum da esfera da produção em seu sentido material). ${ }^{3}$ Essa irredutibilidade da instituição ao polo da produção projeta a teoria como uma espécie de desmaterialização, cuja primeira consequência é um esvaziamento do problema do valor e de sua dupla estruturação no processo de trabalho (trabalho abstrato e concreto) - uma oportunidade perdida pelos autores para debater o tema da crise da sociedade do trabalho, o traba- lho abstrato e a crítica do valor (Wertkritik) com toda uma tradição da crítica marxista presente na produção teórica de Robert Kurz, Anselm Jappe e Moishe Postone.

Se a ênfase de Dardot e Laval recai sobre o fundamento de uma criatividade histórica da instituição, essa teoria do agir deve ser pensada, portanto, como práxis. Cruzando os textos de maturidade de Castoriadis com a situação histórica da práxis no Marx de $O$ 18 de Brumário de Luis Bonaparte a fim de pensar a práxis instituinte como atividade autotransformadora condicionada, Dardot e Laval posicionam a atividade do comum a um só tempo como um fazer (faire) vinculado às estruturas históricas herdadas e uma ação criadora de subjetividade. A práxis instituinte, como autoinstituição da sociedade, efetiva a autonomia sob o princípio do comum. Afınal: “a história não nos mostra autores dirigindo suas ações a partir de um projeto, mas atores sendo produzidos como sujeitos na e através de sua ação" (DARDOT; LAVAL, 2015a, p. 8 - Cap. 10). 0 conteúdo emancipador da práxis instituinte, pensado como um sujeito coletivo, implica que sua inserção na reprodução ampliada do capital produza, sobretudo, novas subjetividades (type d'individus). Talvez aqui os autores paguem o preço político pela aludida desmaterialização da reprodução do capital e da práxis em relação

3. Nesse ponto, em que o princípio do comum como atividade é derivado de sua situação junto à reprodução ampliada do capital (e afastado da produção material como núcleo galvanizador da dinâmica social), fica explícita a divergência das abordagens de Dardot e Laval em relação à clássica trilogia de Hardt e Negri, já que ambos são criticados pelos autores franceses pela proposição de um "espinozismo comunizado", entendendo o comum como desenvolvimento de uma potência, ou seja, uma "ontologia histórica” da potência da multidão (multitude) e da imanência do comum à produção biopolítica. Para os autores franceses, a centralidade da produção nessa ontologização da multidão apaga justamente a especificidade da instituição como princípio irredutível ao intercâmbio material da sociedade. A pertinência ou não da crítica é um debate aberto, pois a apreciação de Dardot e Laval parece apagar momentos conceituais importantes da teoria de Hardt e Negri. 
às dinâmicas de produção: se o comum é um princípio, um fundamento da atividade no sentido da $\dot{\alpha} \rho \chi \eta ́ ~(a r k h \bar{e})$ da metafísica aristotélica, a abordagem de Dardot e Laval não oferece um modelo teórico suficiente para traduzir a produção de subjetividades em atores políticos calcados em relações de produção. Talvez não seja propriamente, como quer Toni Negri (2014), um idealismo baseado em uma racionalidade que funda o real em vez de se fundamentar sobre (sur) ele, mas antes uma indefinição dessas subjetividades e de suas mediações na própria difusão das práticas da governamentalidade neoliberal - o que Hardt e Negri (2012), por exemplo, chamaram de "figuras subjetivas da crise" como o terreno social constitutivo da ação política.

0 que de fato alicerça o comum no intercâmbio da sociedade é certa apreensão do social e de sua confıguração no capitalismo neoliberal. 0 projeto de emancipação do comum e da práxis instituinte assume como fundamento uma dinâmica interna da atividade social. 0 problema, portanto, implica uma análise da consistência do social e de sua estruturação. Como dimensão problemática da atividade humana, o social é diretamente derivado das lutas sociais dos séculos XIX e XX, que o elaboraram como campo de intervenção, criando estruturas que autonomizam essa esfera e seus processos de modernização por meio do reconhecimento de direitos, serviços, assistência e mecanismos de desenvolvimento (saúde, educação, moradia etc.). Como conjunto de dispositivos que atendem a necessidades coletivas, a fundamentação do social é diluída na lógica concorrencial e em sua dominação direta pelas estruturas de mercado da época neoliberal. A crise, como forma de gestão política, é o epígono dessa separação dos indivíduos de sua condição de autonomia como um comum em uma época na qual os mecanismos de soberania política e de legitimidade (dinâmica eleitoral, representação política etc.) ficam esfumaçados sob pressão da fınanceirização, das oligarquias partidárias e da desidratação de direitos sociais (DARDOT; LAVAL, 2015b). Não se trata de uma retomada do social no sentido de seu condicionamento determinado pelo Estado na correção de défıcits, pois o problema da instituição do comum e de sua práxis, antes, reside em uma nova figuração do social como atividade do comum.

Para Dardot e Laval, a condição política fundamental desse movimento está no controle democrático das instituições e do governo pela sociedade em uma direção que está para além do social, ou seja, de um campo de intervenção do Estado para gestão do conflito, controle moral e correção de carências no sentido da manutenção da ordem pública - um regime de soberania política regulado pelo "Estado pastoral", tal como Dardot e Laval (2015a, p. 13 - Proposição Política 6) definem essa antiga figuração do social em uma expressão foucaultiana. 0 princípio do comum estabelece as bases de uma democracia social em que as instituições e os núcleos de decisão política, antes de serem absorvidos pela burocratização estatal, implicam um regime de participação no controle social do que é tornado comum (mis en commun). As dinâmicas do serviço público, nesse sentido, sofrem uma torção conceitual importante: para além da razão funcionalista que, na esteira de Léon Duguit, analisava as atividades públicas e sua correspondência na evolução da diferenciação funcional da sociedade, Dardot e Laval (2015a, p. 6 - Proposição Política 7) afırmam uma reelaboração da cidadania no sentido de um controle democrático por meio do "direito de intervenção, de delibe- 
ração e de decisão" na tradução do serviço público como instituição do comum (justamente reconhecendo a sociedade em sua dimensão de conflito, de mobilização e de resistência à ação do Estado). As bases da solidariedade e dos mecanismos de coesão social, portanto, assumem como eixo o autogoverno do que é comum, possibilitando um novo equacionamento da autonomia da forma social e das clivagens entre sociedade civil e Estado por meio de uma nova figuração do social e de sua determinação política interna.

\section{Referências}

DARDOT, P.; LAVAL, C. Commun: essai sur la révolution au XXIe siècle. Paris: La Découverte, 2015a, E.reader Kobo.

. Le néolibéralisme, un système hors-démocratie. Fevereiro, São Paulo, v. 6, p. 1-13, 2015b. Uma alternativa ao neoliberalismo. Tempo Social, São Paulo, v. 27, n. 1, p. 275-315, 2015c.

HARDT, M.; NEGRI, A. Declaration. Nova York: Argo Navis, 2012.

LUKIC, A.; MASLOV, G. Did somebody say 'transition'?: a critical intervention into the use of a notion. Praktyka Teoretyczna, Poznán, n. 13, p. 203-223, 2014.

NEGRI, T. La metafisica del comune. Il Manifesto, Roma, 5 maio 2014.

SOWA, J. An unexpected twist of ideology. Praktyka Teoretyczna, Poznán, n. 5, p. 153-180, 2012. 
